\title{
Purification and mechanistic characterisation of two polygalacturonases from Sclerotium rolfsii
}

\author{
W. Schnitzhofer ${ }^{\mathrm{a}}$, H.-J. Weber ${ }^{\mathrm{b}}$, M. Vršanskác ${ }^{\mathrm{c}}$, P. Biely ${ }^{\mathrm{c}}$, A. Cavaco-Paulo ${ }^{\text {d }}$, G.M. Guebitz ${ }^{\mathrm{a}, *}$ \\ ${ }^{a}$ Department of Environmental Biotechnology, Graz University of Technology, Petersgasse 12, 8010 Graz, Austria \\ ${ }^{\mathrm{b}}$ Department of Organic Chemistry, Graz University of Technology, Stremayrgasse 16, 8010 Graz, Austria \\ ${ }^{\mathrm{c}}$ Institute of Chemistry, Slovak Acadamy of Sciences, 84238 Bratislava, Slovak Republic \\ ${ }^{\mathrm{d}}$ Department of Textile Engineering, University of Minho, 4800 Guimaraes, Portugal
}

Received 4 August 2006; received in revised form 6 November 2006; accepted 6 November 2006

\begin{abstract}
Sclerotium rolfsii (strain CBS 350.80) was found to produce extraordinary high amounts of polygalacturonases (PGs). Two of these extracellular enzymes were purified by a recently introduced preparative electrophoretic device (isoelectric focusing mode of free flow electrophoresis). PG 1 (39.5 kDa, pI 6.5) and PG 2 (38 kDa, pI 5.4) exhibited quite similar properties, they were found to be both endo-acting enzymes. Both PGs cleaved penta- and trigalacturonic acid while tetragalacturonic acid was only cleaved when trigalacturonic acid was present. The latter substrate was hydrolysed much faster by PG 2. Both enzymes were active on pectins with different degrees of esterification, they were sensitive towards Ca-cations and not glycosylated. The kinetic properties were measured by viscosimetry with polygalacturonic acid as a substrate. NMR experiments on a model substrate revealed an inverting mechanism of carbohydrate hydrolysis for both enzymes.
\end{abstract}

(C) 2006 Elsevier Inc. All rights reserved.

Keywords: Polygalacturonase; FFE; Purification; Pectinase; Plant pathogen fungus

\section{Introduction}

Polygalacturonases belong to the complex of pectin degrading enzymes and within those to the depolymerising group acting hydrolytically. Their substrates are pectic substances, which have a common frame-polymer composed from $\alpha$-1,4-linked galacturonic acid units, more or less esterified [1]. They occur as a structural material in the primary wall and in the middle lamellae of higher plants, showing a high diversity depending on the natural source [2]. PGs are found to be produced by a wide variety of organisms, like bacteria, yeasts, fungi, insects and even plants. The physiological functions of PGs are still in investigation, but the involvement of fungal PGs in the infection processes of plants seem to be evident, one common aspect is often the plant pathogenity of organisms, whereby PGs seem to have an important role within the infection process [3]. Industrially these enzymes are interesting for a growing number of different applications, fruit clarification as the classical applica-

\footnotetext{
* Corresponding author.

E-mail address: guebitz@tugraz.at (G.M. Guebitz).
}

tion, a new field came up, when the potential of pectic substances as dietary fibres was recognised, the preparation of oligosaccharides from pectic polymers and the latest application in the field of cotton processing, PGs were successfully applied in socalled bioscouring sequences [4]. As a suitable organism for industrial production of PG the fungus A. niger is used, not only because of the extraordinary amounts of enzyme produced, but also because concomitant synthesis of several substances is possible [5]. Another well investigated fungus known to produce PG is the plant pathogen basidiomycete Sclerotium rolfsii. The strain CBS 350.80 was found to produce extraordinary high amounts of these enzymes, anyway one of the highest reported activity values and therefore explored in detail.

Most polygalacturonases have been purified from the fermentation broth by means of chromatographic methods, especially ionexchange and affinity chromatography were applied, as was reviewed by Ref. [6]. The technique of the so-called free flow electrophoresis (FFE) has been developed for continuous separation of molecular and particular substances, e.g. whole cells, organelles, polymers. Particles are processed in a free fluid system, where no matrices forming networks influence their electrophoretic mobility. Successful separation of proteins by 
free flow zone electrophoresis were promising [7,8]. Resolution could be appreciably increased by the introduction of other electrophoretic modes, isoelectric focusing (IEF) and isotachophoresis (ITP). Even so, FFE is until now not a commonly used method for enzyme purification.

Enzymes hydrolysing glycosidic linkages of oligo-, polysaccharides and glycosides utilize two different reaction mechanisms leading to a different configuration of the newly formed reducing end [9]. The hydrolysis can be catalyzed in one chemical step - single displacement mechanism - generating reducing-end products with a configuration of the anomeric carbon reversed to that of the cleaved glycosidic linkage. Such enzymes are called inverting. Another group of hydrolases utilize two chemical steps - double displacement mechanism - to perform the cleavage of the glycosidic linkage. Such enzymes are called retaining. In contrast to cellulases and hemicellulases, there is much less information available about the hydrolysis mechanism of pectinases. In this study, we compare the substrate specificities of two new polygalacturonases from $S$. rolfsii.

\section{Materials and methods}

\subsection{Organism and culture conditions}

Sclerotium rolfsii (CBS 350.80) was obtained from the University of Agricultural Sciences, Vienna, Austria. The culture was maintained on potatodextrose-agar (PDA) plates grown at $30^{\circ} \mathrm{C}$, stored at $4{ }^{\circ} \mathrm{C}$ and subcultured monthly. For PG production $S$. rolfsii was grown in $1000 \mathrm{ml}$ Erlenmeyer flasks at $30 \pm 1{ }^{\circ} \mathrm{C}$ on an orbital shaker at $150 \mathrm{rpm}$ using $300 \mathrm{ml}$ culture medium containing the following ingredients: $42.6 \mathrm{~g}$ cellulose, $40 \mathrm{~g}$ meat peptone, $2.5 \mathrm{~g}$ $\mathrm{NH}_{4} \mathrm{NO}_{3}, 1.5 \mathrm{~g} \mathrm{MgSO}_{4}, 1.0 \mathrm{~g} \mathrm{KH}_{2} \mathrm{PO}_{4}, 0.5 \mathrm{~g} \mathrm{KCl}$, and $300 \mu \mathrm{l}$ trace element solution in 11 distilled water [10]. The initial $\mathrm{pH}$ was adjusted to 5 and the growth medium was sterilized at $121^{\circ} \mathrm{C}$ for $15 \mathrm{~min}$ prior to inoculation with $1 \mathrm{~cm}^{2}$ discs of fungus growing on agar plates. In order to induce polygalacturonase activity pectin $\left(1 \mathrm{~g}^{-1}\right)$ was added to the fermentation broth after being sterilized by UV radiation over night to prevent hydrolysis at the point of inoculation. The fermentation continued for a total of 10 days after which the culture supernatant was harvested by centrifugation at $10,000 \times g$ for $10 \mathrm{~min}$.

\subsection{Enzyme and protein assay}

PG activity was measured by determination of reducing sugars released as a result of hydrolysis of sodium polypectate by a dinitrosalicylic acid (DNS) reagent [11]. The reaction volume was adapted to the volumetric capacity of an Eppendorf vessel. The mixture containing $450 \mu 10.25 \%$ PGA solution in buffer $\mathrm{pH} 5$ and $50 \mu \mathrm{l}$ of appropriately diluted enzyme solution was incubated at $50{ }^{\circ} \mathrm{C}$ for $5 \mathrm{~min}$ and the reaction stopped by addition of $750 \mu \mathrm{l}$ of DNS. After boiling for $5 \mathrm{~min}$, subsequent cooling and centrifugation the absorbance was read at $540 \mathrm{~nm}$. The reducing sugars formed were quantified using D-galacturonic acid as a standard. Activity on other substrates was measured similarly. One unit (U) was defined as the amount of enzyme that releases $1 \mu \mathrm{mol}$ of reducing sugar per minute.

Protein concentration was routinely determined using the Bradford Reagent from Bio-Rad [12] according to the manufacturer's instructions (Bio-Rad) with bovine serum albumin as standard. Dependent on the concentration range the micro or microplate assay has been applied. All chromatographic runs were monitored for protein by absorbance at $280 \mathrm{~nm}$.

\subsection{Enzyme purification}

\subsubsection{Precipitation}

The supernatant of the $S$. rolfsii fermentation was subjected to fractionation by ammonium sulphate precipitation at $50 \%$ saturation to remove some proteins, followed by $95 \%$ saturation in a second step to gain most of the PG activity. The pellet was resuspended in $50 \mathrm{mM}$ Na-acetate buffer $\mathrm{pH} 4$ and dialysed against distilled water.

\subsubsection{Free flow electrophoresis}

FFE separations were performed with the ProTeam FFE (Tecan GmbH, Austria) using the isoelectric focussing mode. Hydroxypropylmethylcellulose (HPMC from Sigma, Germany) provided the laminar flow within the chamber. Following media were applied:

Anodic stabilisation medium: 25\% (w/w) glycerol, HPMC, $100 \mathrm{mM} \mathrm{H}_{2} \mathrm{SO}_{4}$. Separation medium 1: $25 \%$ (w/w) glycerol, HPMC, $14.3 \%$ Prolyte $^{\mathrm{TM}} 1, \mathrm{pH}$ ca. 4.

Separation medium 2: 25\% (w/w) glycerol, HPMC, $20.0 \%$ Prolyte $^{\mathrm{TM}}$ 2, $\mathrm{pH}$ ca. 7 .

Separation medium 3: 25\% (w/w) glycerol, HPMC, $14.3 \%$ Prolyte $^{\mathrm{TM}} 3, \mathrm{pH}$ ca. 9.7.

Cathodic stabilisation medium: 25\% (w/w) glycerol, HPMC, $100 \mathrm{mM} \mathrm{NaOH}$. Counterflow medium 25\% (w/w) glycerol, HPMC.

Anodic circuit electrolyte (sulfuric acid standard solution $1 \mathrm{~mol} / \mathrm{l}$, Riedel-de Häen), cathodic circuit electrolyte (sodium hydroxide $\geq 99 \%$, p.a., ROTH).

The concentration of hydroxypropylmethyl cellulose (HPMC) was dependent on the protocol applied $-0.2 \%(\mathrm{w} / \mathrm{w})$ for the high HPMC protocols, and $0.05 \%(\mathrm{w} / \mathrm{w})$ for the low HPMC protocol. The sample from precipitation was diluted 1:2 with equal parts of HPMC and glycerol (50\% sample $+25 \%$ solution of $0.8 \%$ HPMC $+25 \%$ glycerol) to reach appropriate viscosity and density. Furthermore, $5 \mu \mathrm{l}$ of a $1 \%$ solution of the red acidic dye 2-( $p$-sulphophenylazo)1,8-dihydroxy-3,6-naphtalenedisulfonic acid trisodium salt was added to $1 \mathrm{ml}$ of sample to ease the optical control of the migration within the separation chamber.

Before every trial the whole system has been prerunned for about $30 \mathrm{~min}$, to equilibrate conditions, like current, temperature and media flow and to prefocus the ampholytes. The quality of the laminar flow across the chamber was checked by a so-called stripe test, whereby coloured $\mathrm{p} I$ markers were loaded to the chamber and collected in a microplate.

The chamber temperature was kept at a constant temperature of $10^{\circ} \mathrm{C}$ by a cooling unit during the run. PGs were localized by activity measurements and most interesting fractions analysed by SDS-PAGE.

\subsubsection{Gelfiltration}

Samples from low HPMC protocols were directly applied to a gelfiltration column. The concentrated sample $(200 \mu \mathrm{l})$ was loaded onto a Superdex $200 \mathrm{HR}$ 30/10 (Amersham Pharmacia Biotech) column and proteins eluted by flushing with $50 \mathrm{mM}$ citrate buffer $\mathrm{pH} 6$ containing $0.1 \mathrm{M} \mathrm{NaCl}$. The active fractions were analysed by SDS-PAGE.

\subsubsection{Control of $p H$ gradient and $p I$ determination}

The $\mathrm{pH}$ values of the individual FFE microtiter plate fractions were measured manually with a pH microelectrode (Schott, N5900 A). The $\mathrm{p} I$ values were calculated by taking the $\mathrm{pH}$ according to the active fractions.

\subsection{Electrophoresis and staining}

SDS gel electrophoresis was performed according to the method of Ref. [13], using 10\% gels and Coomassie Blue for protein staining. To detect PG activity directly on the gel an adapted procedure described for cellulases has been applied [14]. SDS was omitted and a $0.3 \%$ (w/v) PGA solution incorporated into the separating gel (resulting a final concentration of $0.1 \%$ ). After electrophoresis and incubation on a sponge, soaked with buffer for $2 \mathrm{~h}$, the gel was stained with $0.02 \%$ Congo red solution for $15 \mathrm{~min}$, washed with $1 \mathrm{M} \mathrm{NaCl}$ solution for another $15 \mathrm{~min}$ and treated with acetic acid solution to increase the contrast.

\subsection{Determination of temperature-pH optima and stabilities}

The pH-temperature profile for the activity of the PGs was compiled by applying the standard enzyme assay at selected temperatures ranging from 30 to $80^{\circ} \mathrm{C}$ and at various $\mathrm{pH}$ values between $\mathrm{pH} 2.5$ and 7.9 using substrate solutions 
in constant ionic strength citrate-phosphate buffer. In each case the substrate was preincubated at the required temperature.

To evaluate the thermal stability aliquot amounts of desalted, concentrated enzyme samples were diluted with $50 \mathrm{mM}$ citrate buffer of various $\mathrm{pH}$ values (pH 3.5, 5, 6.5 and 8) and incubated for fixed time periods at 30,50 and $70^{\circ} \mathrm{C}$. At time intervals samples were withdrawn, cooled on ice before assaying to determine the residual enzyme activity, using the normal assay procedure.

\subsection{Effect of cations and surfactants}

Out of a big number of potential inhibitors several have been chosen: $\mathrm{Fe}(3)$, $\mathrm{Hg}(2), \mathrm{Ca}, \mathrm{Mg}$ (as chloride salts each), $\mathrm{K}_{2} \mathrm{CrO}_{4}$, SDS, EDTA, and the surfactants Triton X-100, Cotemoll.

An appropriate amount of purified enzyme solution has been incubated with different concentrations of inhibitors (by dilutions of a $100 \mathrm{mM}$ stock solution) for $10 \mathrm{~min}$ at room temperature and activity measured. The starting conditions have been checked out within preexperiments, the concentration range varied from 0.05 to $50 \mathrm{mM}$, dependent on the inhibitor, the surfactants have been applied in a concentration of $0.05 \%$.

\subsection{Degree of glycosylation}

Possible glycosylation residues were removed enzymatically by treating pure enzyme samples with a glycosidase and an amidase (both New England Biolabs Inc.).

Deglycosylation with Endoglycosidase $\mathrm{H}$ (EndoH): $2 \mu$ l of $10 \times$ denaturing buffer $(0.5 \%$ SDS, $1 \% \beta$-mercaptoethanol $)$ were added to $18 \mu$ l of protein sample and heated to $100^{\circ} \mathrm{C}$ for $10 \mathrm{~min}$, after cooling down the mixture was incubated in G5 Buffer ( $2.25 \mu$ l of $10 \times$ buffer, $50 \mathrm{mM} \mathrm{Na}$-citrate) and $2.25 \mu \mathrm{l}$ of EndoH at $37^{\circ} \mathrm{C}$ for $24 \mathrm{~h}$.

Deglycosylation with peptide: $N$-glycosidase F (PNGase F): $2 \mu l$ of $10 \times$ glycoprotein denaturing buffer $(0.5 \%$ SDS, $1 \% \beta$-mercaptoethanol) were added to $18 \mu \mathrm{l}$ of protein sample and heated to $100^{\circ} \mathrm{C}$ for $10 \mathrm{~min}$, after cooling down the mixture was incubated in G7 reaction buffer $(2.5 \mu l$ of $10 \times$ buffer, $50 \mathrm{mM}$ Na-phosphate), supplemented with $2.5 \mu 1$ 10\% NP-40, and $2.5 \mu \mathrm{l}$ of PNGaseF at $37^{\circ} \mathrm{C}$ for $24 \mathrm{~h}$.

The deglycosylation was controlled by applying treated and untreated samples to a SDS-PAGE.

\subsection{Change in specific viscosity}

Enzyme action on PGA was followed by measuring the increase in reducing groups and reduction in viscosity. The viscosity was determined at a fixed temperature of $30^{\circ} \mathrm{C}$ with an AMVn automated mircoviscosimeter (Anton Paar ${ }^{\circledR}$ $\mathrm{GmbH}$, Graz, Austria). For the calculation, it was necessary to determine the density, performed with the DMA 38 density meter (Anton Paar ${ }^{\circledR} \mathrm{GmbH}$, Graz, Austria) by filling the sample loop with the sample liquid and after a certain equilibration time reading the density. A $975-997.5 \mu \mathrm{l}$ of a $0.5 \%(\mathrm{w} / \mathrm{v})$ polygalacturonic acid in $50 \mathrm{mM}$ acetate buffer $(\mathrm{pH} 5)$ was preincubated at $30^{\circ} \mathrm{C}$ and mixed with $2.5-25 \mu l$ of the purified enzymes. The mixture was carefully (to prevent air bubbles) filled into the capillary with $1.6 \mathrm{~mm}$ diameter. The capillary was put into the AMVn and the decrease of viscosity was monitored at an angle of $70^{\circ}$ till no substantial change was observed. The released reducing sugars of similar reaction mixtures were measured with the DNS method.

\subsection{Determination of kinetic parameters}

Kinetic properties of the PGs were determined by the measurement of viscosity changes of homogalacturonan solutions in $50 \mathrm{mM}$ acetate buffer $\mathrm{pH} 5$ and $30^{\circ} \mathrm{C}$, incubated with a certain amount of enzyme similar to the above described measurements. Tested substrate concentrations were in the range of 0.5-10 g/l. Michaelis-Menten parameters were calculated from Eadie-Hofsted plots $V$ versus $V /[\mathrm{S}]$ plots and Hanes-Woolf plots [S]/V versus [S], where [S] is the substrate concentration and $V$ is the initial rate of hydrolysis. By combination of the two methods, mean values were calculated.

\subsection{Release of oligosaccharides}

Oligogalacturonic acids of degree of polymerisation 2-5 were prepared by enzymatic hydrolysis of citrus pectin followed by chromatographic purification of the fragments. The reaction of PGs with oligogalacturonic acid was performed in Eppendorfs, in a minimized scale, a total volume of $20 \mu 1$, containing $20 \mathrm{mM}$ of oligomer in $10 \mathrm{mM}$ acetate buffer $\mathrm{pH} 5$ and a standardized amount of enzyme, which was evaluated in preexperiments. The reaction temperature was set to $30^{\circ} \mathrm{C}$ and the reaction controlled by TLC. Samples were withdrawn out of the reaction mixture in certain time intervals and two times $0.5 \mu 1$ spotted on a TLC plate $(20 \mathrm{~cm} \times 20 \mathrm{~cm}$, aluminium sheets, silica gel 60 from Merck), dried with a hair-drier after every spot to stop the enzyme reaction and put in a chamber saturated with the running solvent 1-butanol-formic acid-water $=2: 3: 1(\mathrm{v} / \mathrm{v})$, after the run was complete, the plate was taken out, dried and the oligosaccharide spots were developed with orcinol solution (containing $1 \mathrm{~g}$ orcine monohydrate from Fluka in $5 \mathrm{ml} \mathrm{H}_{2} \mathrm{SO}_{4}$ conc. and $95 \mathrm{ml}$ ethanol) by pouring a homogenous layer over the plate, drying the same and heating up to $100^{\circ} \mathrm{C}$ in a dry chamber, where the spots became dark coloured.

\subsection{Substrate specificities and side activities}

Polygalacturonases were tested for their specificities on following substrates: apple pectin (70-75\%) and citrus pectin (63-66\%), both Fluka and for their side activities on xylan from birchwood (Roth), mannan from S. cerevisiae (Sigma) and CMC (Merck). The experiments were carried out in principle as described before.

The reaction mixtures contained $0.5 \%$ of the different substrates in $10 \mathrm{mM}$ acetate buffer $\mathrm{pH} 5$ and always the same amount of enzyme. The reaction temperature was set to $30^{\circ} \mathrm{C}$. Evaluation was done by reducing sugar determination and TLC.

\subsection{Elucidation of the reaction mechanism}

\subsubsection{Sample preparation}

The purified enzyme samples of polygalacturonases 1 and 2 were concentrated (Vivaspin 6), simultaneously desalted by washing with $\mathrm{D}_{2} \mathrm{O}$ (Sigma) several times and two times lyophilized for being redissolved in $\mathrm{D}_{2} \mathrm{O}$ immediately before use in ${ }^{1} \mathrm{H}$ NMR experiments.

\subsubsection{Substrate preparation}

PentaGalU-ol was prepared by $\mathrm{NaBH}_{4}$ reduction of the corresponding aldouronic acid and lyophilized three times from $\mathrm{D}_{2} \mathrm{O}$.

\subsubsection{Reaction mixtures for ${ }^{1} H$ NMR spectroscopy}

A $20 \mathrm{mM}$ of pentaGalU-ol was dissolved in $0.05 \mathrm{M}$ deuterized acetate buffer $\mathrm{pH} 5$ and $0.1 \mathrm{ml}$ of a suitable concentrated enzyme solution to $0.4 \mathrm{ml}$ of this substrate added. The amount of enzyme was determined by TLC experiments as described before, and should guarantee the hydrolysis rate to be much higher than mutarotation of the newly formed reducing end. ${ }^{1} \mathrm{H}$ NMR spectra of the reaction mixture were recorded versus time on a varian unity inova 500 spectrometer at $30^{\circ} \mathrm{C}$. The assignment of important resonances was based on published data [15].

\section{Results and discussion}

Sclerotium rolfsii was found to produce high amounts of polygalacturonase activity. The substrate specificities and properties of the enzymes responsible for this activity are compared in this study.

\subsection{Production of polygalacturonases by $S$. rolfsii}

The cellulose containing basal medium used during these experiments was selected because it assured excellent growth of 


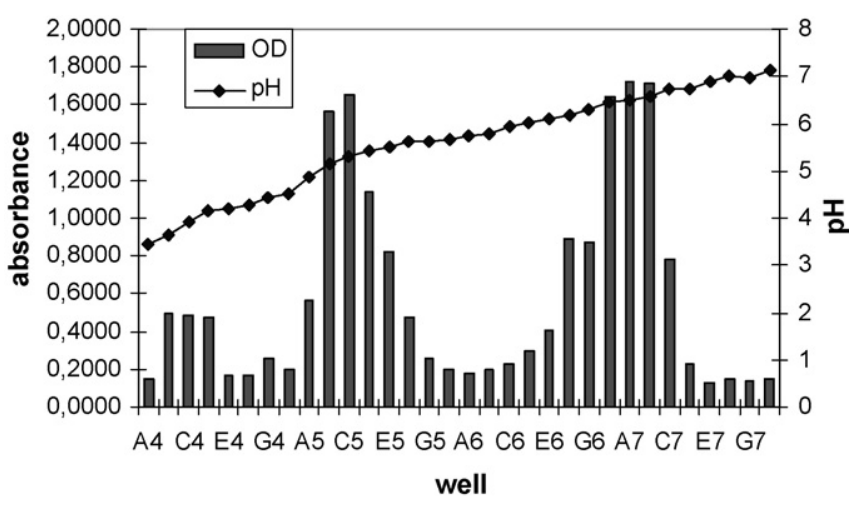

Fig. 1. Analysis of a FFE run, activity distribution of PGs and $\mathrm{pH}$ gradient $(X-$ axis displays well number according to the common labelling of a microtiter plate).

the fungus, and because cellulose was reported to provide PG production [16]. As a highest value a considerable PG activity of $300 \mathrm{U} / \mathrm{ml}$ was measured after 10 days in the basal medium. The amount of PG could be increased by adding pectin, but the extent of $25 \%$ was more moderate than one could expect. However, the values for PG activities obtained have been one of the highest reported in literature. The potential of several inducers have been assessed and reported elsewhere [17].

\subsection{Native PAGE}

In order to know number, molecular weight and $\mathrm{p} I$ of different PGs, native PAGE is a very helpful tool. The most commonly applied overlay method reported in literature [18] did not work properly, it resulted as its best in large, diffuse spots, but an allocation to certain bands was not possible. The contact area is assumed to be the crucial point of the overlay technique-to allow enzymes diffusing from the gel into the overlay to react with the substrate. A better result was obtained with an adapted method according to Ref. [14], although not described for PGs, as shown in Fig. 1, a slightly visible double band appeared in the middle of the gel.

\subsection{Purification of two PGs from S. rolfsii}

\subsubsection{Precipitation}

This step was performed as a purification step to remove unwanted substances and proteins, as well as a concentration step by resuspending the pellet in a less amount of buffer. The best purification effect could be achieved by fractionated precipitation between 50 and $95 \%$ saturation of ammonium sulphate. The efficiency of the precipitation step was rather high, considering the reduction of the total protein amount by $42 \%$ and the yield of recovered PG of more than $97 \%$.

\subsubsection{Free flow electrophoresis (FFE)}

Several trials have been run in order to find the best adjustment of the system parameters to optimize focusing, medium flow-rate, sample flow and chamber gap $(0.4 \mathrm{~mm})$.

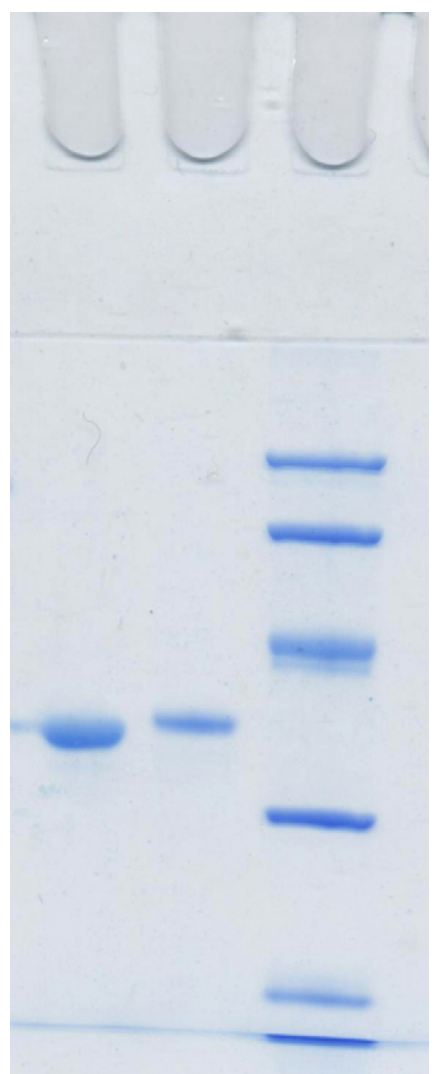

Fig. 2. SDS-PAGE of purified enzymes from FFE; samples applied from left to right: PG2, PG 1 and molecular weight standards $(97.4,66.2,45,31,21.5$, $14.4 \mathrm{kDa})$.

A high HPMC protocol was run to set the conditions and then changed to a low protocol to collect the samples. PG activity measurements revealed three activity peaks at different $\mathrm{pH}$ values (Fig. 2). It was conspicuously, that the activity measured for the first peak (well B4, C4 and D4) was much lower compared to both others. SDS (data not shown) analysis revealed a number of proteins being present in these fractions, whereas excellent separation was achieved for fractions B5, C5 and H6, A7 and B7, although there were some other protein bands present. Subsequently the two peaks with the higher activity were selected for further upgrading. For complete purification and for removal of the matrix substances, particularly the HPMC, fractions of the two main peaks were subjected to a gelfiltration step. As displayed in Fig. 3, clear defined bands were obtained indicating pure enzyme fractions.

To calculate the activity retrieval, pumps were calibrated, the sample focused for exactly $10 \mathrm{~min}$ and collected in a microplate. Out of $227 \mathrm{IU}$ applied, $219 \mathrm{IU}$ were found in 22 active fractions, $11.4 \%$ in peak $1,27.1 \%$ in peak 2 and $58.0 \%$ in peak 3 -that is a recovery of $96.5 \%$.

\subsubsection{Determination of $M W$ and $p I$}

The PGs from FFE have been compared by SDS page analysis and calibration with molecular standards yielded molecular weights as listed in Table 1 . The $\mathrm{p} I$ was averaged out of numerous trials from FFE. The enzyme with the higher $\mathrm{p} I$ was named PG 1, the one with lower $\mathrm{p} I$ PG 2. 


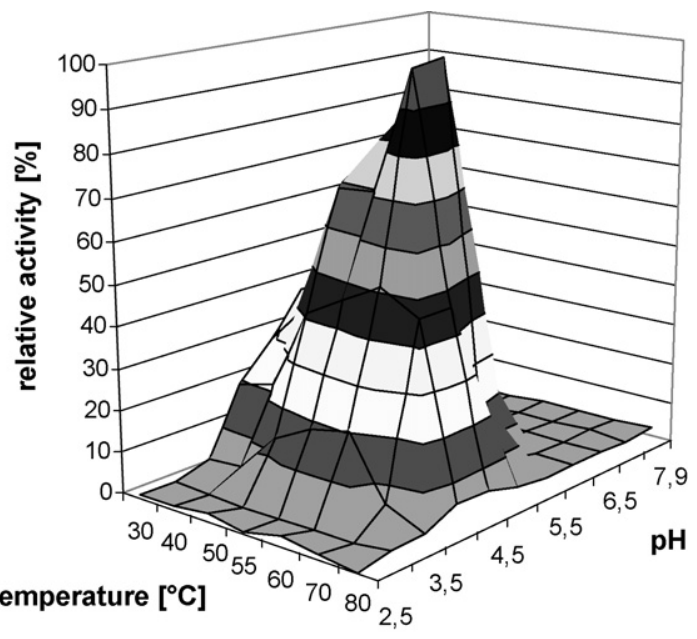

(a)

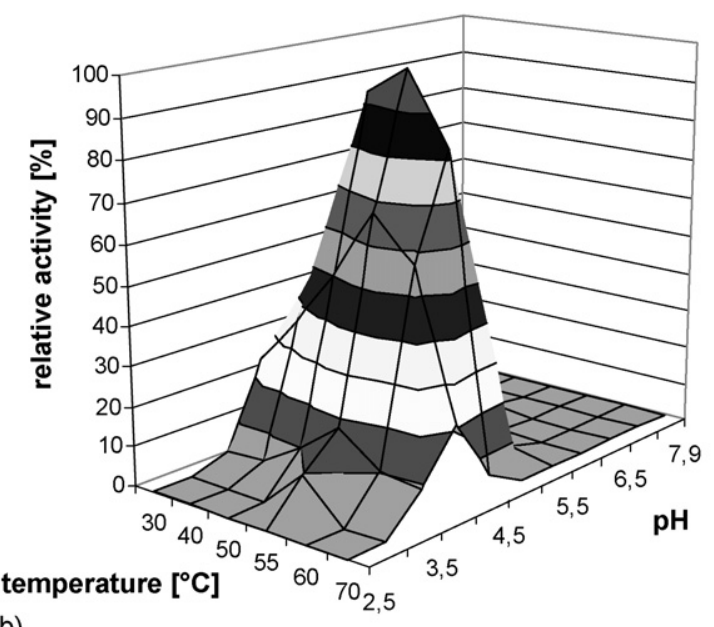

(b)

Fig. 3. Activity profiles at different $\mathrm{pH}$ and temperature values of (a) $\mathrm{PG} 1$ and (b) PG 2.

The advantages of the FFE method are obvious, continuous separation with high resolution. Detection of number of enzymes with differences in their $\mathrm{p} I$ and estimation of $\mathrm{p} I$, thus it is not only a preparative, but also an analytical method. Out of the FFE experiments informations were obtained, which were of big importance for establishing a successful purification strategy. Reviewing the literature, two reports about purification of PGs from $S$. rolfsii were found. An acid-stable endo-PG with an $\mathrm{pH}$ optimum of 2.5 was purified by precipitation and five chromatographic steps Sephadex G-100, DEAE cellulose, Sephadex G-200, SE-Sephadex C-50 and Sephadex G-100 239-fold in a yield of $3.8 \%$ [17] and two different polygalacturonases were separated by ammonium sulphate precipitation 80-95\% and two chromatographic steps, DEAE-cellulose $\mathrm{pH} 8$ and Sephadex G-

Table 1

Molecular weight and isoelectric point of purified polygalacturonases from $S$. rolfsii

\begin{tabular}{lll}
\hline & MW (kDa) & $\mathrm{p} I$ \\
\hline PG 1 & 39.5 & $6.5 \pm 0.2$ \\
PG 2 & 38 & $5.3 \pm 0.1$ \\
\hline
\end{tabular}

$75, \mathrm{pH} 4.5$, revealing a smaller enzyme with an MW of 28-31 and a larger enzyme with $46-48 \mathrm{kDa}$ [19]. These described enzymes differ from the enzymes purified in this work. This is not surprising, since the authors had studied different strains of $S$. rolfsii. Previously, surprisingly high variations in terms of number and amount of hemicellulolytic enzymes, produced by different strains of $S$. rolfsii had been reported [21].

\section{Biochemical characterisation}

\subsubsection{Activity optima and enzyme stabilities}

PG 1 was optimally active at $\mathrm{pH} 5$ and $60^{\circ} \mathrm{C}$ while $\mathrm{PG} 2$ had its activity optimum at $\mathrm{pH} 4.5$ and $55^{\circ} \mathrm{C}$. Both enzymes exhibited well defined activity peaks at different $\mathrm{pH}$ and temperature values (Fig. 4). $\mathrm{PG} 1$ was quite stable at $50^{\circ} \mathrm{C}$ and $\mathrm{pH} 5$ but exhibited more sensitivity against $\mathrm{pH}$ values below and above 5; at $70^{\circ} \mathrm{C}$ the stabilities were drastically reduced. PG 2 turned out to be a really sensitive enzyme, its half-life time at $50^{\circ} \mathrm{C}$ was in the range of minutes and at $70^{\circ} \mathrm{C}$ the enzyme was inactivated within 1 min (Table 2).

\subsubsection{Effect of Inhibitors}

Potential inhibitors of PGs have been tested up to concentrations of $50 \mathrm{mM}$. Fe(II) could not be examined, since it was immediately oxidised by the DNS reagent giving a positive response even without enzyme and was therefore replaced by $\mathrm{Fe}(\mathrm{III}) . I_{50}$ values are shown in Table 4 . PG 1 and PG 2 were

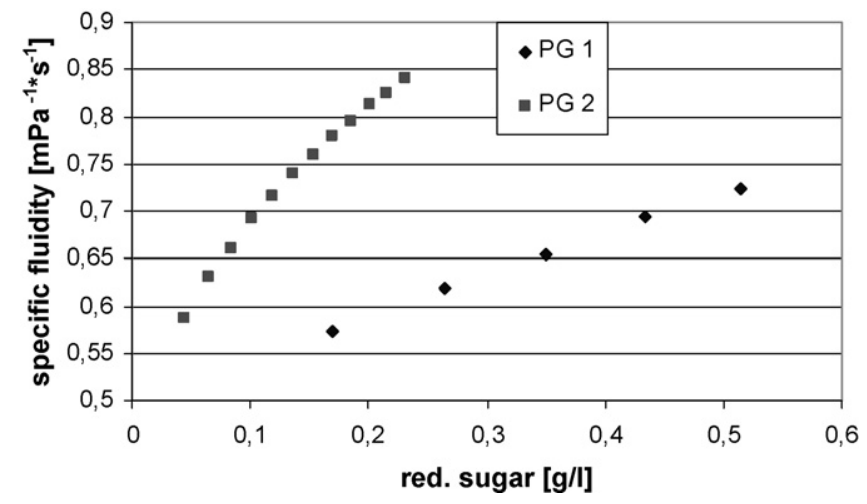

Fig. 4. Relationship between the specific fluidity of polygalacturonic acid and the released reducing sugars during hydrolysis by the purified polygalacturonases of S. rolfsii.

Table 2

Half-life times of two polygalacturonases from S. rolfsii at different conditions

\begin{tabular}{lllr}
\hline $\mathrm{pH}$ & Temperature $\left({ }^{\circ} \mathrm{C}\right)$ & PG 1 & PG 2 \\
\hline 3.5 & 50 & $160 \mathrm{~min}$ & $45 \mathrm{~min}$ \\
& 70 & $30 \mathrm{~min}$ & $<1 \mathrm{~min}$ \\
5 & 50 & $48 \mathrm{~h}$ & $40 \mathrm{~min}$ \\
& 70 & $50 \mathrm{~min}$ & $<1 \mathrm{~min}$ \\
6.5 & 50 & $80 \mathrm{~min}$ & $5 \mathrm{~min}$ \\
& 70 & $20 \mathrm{~min}$ & $<1 \mathrm{~min}$ \\
\hline
\end{tabular}


strongly inhibited by $\mathrm{Ca}(\mathrm{II})$, but less by $\mathrm{Mg}(\mathrm{II}) . \mathrm{Hg}(\mathrm{II}), \mathrm{Fe}(\mathrm{III})$ and SDS were found to be stronger inhibitors for PG 1 than for PG 2, for $\mathrm{Cr}(\mathrm{VI})$ the opposite was true. EDTA and surfactants did not influence enzyme activity. Comparison of these results with literature values is problematic, since different conditions were applied for inhibition experiments. Multiple forms of polygalacturonases from A. carbonarius were insensitive towards a number of metal ions including $\mathrm{Ca}, \mathrm{Mg}$ and $\mathrm{Fe}$, except $\mathrm{Hg}(\mathrm{II})$, incubated in $9.5 \mathrm{mM}$ chloride salt for $15 \mathrm{~min}$ [22]. A purified PG from S. sclerotiorum was $75 \%$ inhibited by $\mathrm{Ca}(\mathrm{II})$ at $2 \mathrm{mM}$, but not sensitive to other divalent cations, including $\mathrm{Hg}$ (II) and EDTA, respectively [23].

\subsubsection{Extent of glycosylation}

The extent of glycosylation was determined enzymatically, whereby two different enzymes were applied. Endoglycosidase $\mathrm{H}$ is a glycosidase, which cleaves the chitobiose core of high mannose and some hybrid oligosaccharides from $N$-linked glycoproteins and PNGase F is an amidase, which cleaves between the innermost GlcNAc and asparagine residues of high mannose, hybrid and complex oligosaccharides from $N$-linked glycoproteins.

With both enzymes the same result was obtained. Neither PG 1 nor PG 2 seemed to be glycosylated or could not be revealed by SDS analysis (pictures not shown).

In accordance a PG of Armillaria sp. was reported to be not glycosylated as fungal PGs in general were supposed to be [24]. Low degree of glycosylation was found for a PG from $A$. alternata [25] and M. flavus [26], where mass differences in the range of a single hexose group and $\mathrm{N}$-acetylhexosamine, respectively, were detected. Multiple forms of polygalacturonases from Aspergillus sp. have glycoprotein character, whereby deglycosylation lead to complete inactivation of tested enzymes [27]. Similarly, several PGs from S. sclerotiorum were found to be glycosylated [28] and differential glycosylation could be responsible for multiplicity of enzyme systems of the same organism [23].

\subsection{Substrate specificities and mechanism of hydrolysis}

\subsubsection{Hydrolysis of oligosaccharides}

The two polygalacturonases were incubated with di- to pentamer of $\alpha$-D-galacturonic acid and the reaction was prosecuted by TLC. None of the PGs hydrolysed digalacturonic acid. Both enzymes cleaved the trimer yielding equal amounts of the diand monosaccharide. Interestingly, although the enzymes were dosed based on the same activity on polygalacturonic acid $(30 \mathrm{IU} / \mathrm{ml})$, complete hydrolysis of the trimer was observed after $6 \mathrm{~h}$ in the case of PG 1 while PG 2 acted much faster completely hydrolysing the trimer after $1 \mathrm{~h}$.

None of the enzymes hydrolysed tetragalacturonic acid although this substance seemed to be degraded in the presence of other oligomers. Reaction of PG 1 with the pentamer yielded in several smaller oligosaccharides including tetragalacturonic acid. After 15 min equal amounts of penta- and tetramer were detected and some amounts of tri-, di- and monosaccharide, after
Table 3

Relative activity in \% of two PGs from S. rolfsii on different pectins normalized to activity on PGA

\begin{tabular}{lcc}
\hline & PG 1 & PG 2 \\
\hline Apple pectin & 9 & 19 \\
Citrus pectin & 13 & 17 \\
Polygalacturonic acid & 100 & 100 \\
\hline
\end{tabular}

$1 \mathrm{~h}$ the pentamer was completely hydrolysed and equal amounts of tetra- and dimer came up. After $2 \mathrm{~h}$ the tetramer disappeared yielding some trimer and monomer but primarily digalacturonic acid, the trimer was further hydrolysed as described before. PG 2 showed again the same pattern with a higher reaction rate compared to PG 1 (as described for the trimer). The fact that the tetramer was further hydrolysed in the course of pentagalacturonic acid degradation could be an indication of certain steric restrictions within the active site of the enzymes, connoting a number of sub-sites has to be filled with galacturonic acid units in order to provide cleavage of oligomers. This result was confirmed when the enzymes were incubated with equal amounts of tetragalacturonic acid and trigalacturonic acid. Interestingly, in the presence of trigalacturonic acid both enzymes were able to hydrolyse tetragalacturonic acid.

In general PGs exhibit lower reaction rates the shorter the oligosaccharides are. A PG from Mucor flavus rapidly hydrolysed oligomers DP 5-7 to mono-, di-, tri- and tetramer, but very slowly the oligomers DP 2-4, which accumulated in all reaction hydrolysates [26]. The PG from F. moniliforme hydrolysed several oligomers from DP 3 to 7 while the dimer was not attacked [29].

\subsubsection{Hydrolysis of different polysaccharides}

Apple pectin with a degree of esterification (DE) of 70-75\% and citrus pectin with a DE of 63-66\% were compared with PGA (all of them in concentrations of $0.5 \%$ ) (Table 3). Compared to PGA, polymethoxygalacturonic acids like apple and citrus pectin were worse substrates for both enzymes with a more pronounced effect for PG 2. Sakai et al. [1] doubted the existence of a so-called polymethylgalacturonase (PMG), although there were numerous publications about such enzymes produced by A. niger [30,31]. Well, in 1997 the same authors reported the expression of a gene encoding for an enzyme in $T$. penicilla-

Table 4

Calculated $I_{50}$ values in $\mathrm{mM}$ (values in brackets are relative activities at $50 \mathrm{mmol}$ of corresponding substance)

\begin{tabular}{lll}
\hline & PG 1 & PG 2 \\
\hline $\mathrm{Ca}(\mathrm{II})$ & 7 & 15 \\
$\mathrm{Mg}(\mathrm{II})$ & $>50(90 \%)$ & $>50(55 \%)$ \\
$\mathrm{CrO}_{4}$ & 32 & 18 \\
$\mathrm{Fe}(\mathrm{III})$ & 0.75 & 16 \\
$\mathrm{Hg}(\mathrm{II})$ & 0.07 & 0.9 \\
$\mathrm{SDS}$ & 0.5 & 12 \\
EDTA & $>50(90 \%)$ & $>50(83 \%)$ \\
Triton X-100 & $(87 \%)$ & $(91 \%)$ \\
Cotemoll & $(82 \%)$ & $(90 \%)$ \\
\hline
\end{tabular}


tum, which was only degrading polymethoxygalacturonic acid and not PGA [32]. Although PG 1 obviously cleaved apple and citrus pectin as indicated by the release of reducing sugars, no small oligomers were detected using TLC. In contrast, hydrolysis of PGA resulted in the formation of small oligomers. Unlike PG 1, PG 2 released oligomers from apple and citrus pectin as well as from PGA.

Generally PGs show lower activity on esterified pectin. The PG from A. carbonarius exhibited only 5\% activity on apple and citrus pectin compared to its action on PGA [22] and 2-5\% on $75 \%$ esterified pectin for several PGs of A. niger N400 [33].

None of the two PGs from $S$. rolfsii exhibited activity towards xylan and carboxymethylcellulose as determined by the release of reducing sugars. In contrast TLC experiments revealed some hydrolysis of xylan and CMC for PG 2, but not for mannan, PG 1 showed in agreement to the above mentioned measurements no reaction products.

\subsubsection{Mechanism of hydrolysis}

4.2.3.1. Viscosimetry. PG 1 and 2 decreased viscosity of a PGA solution rapidly, whereby $\mathrm{PG} 2$ exhibited a faster reduction of viscosity compared to PG 1 . The course of viscosity and corresponding reducing sugars is shown in Fig. 4. Both polygalacturonases from $S$. rolfsii show an endo mode of action. Comparing the slopes of the regression curves, PG 2 decreased the viscosity of a PGA solution about four times faster than PG 1 based on the same number of cleavages performed (reducing ends generated) indicating the higher endo character of PG 2. A rapid decrease in viscosity relative to reducing groups liberation indicates that internal glycosidic bonds of the polymer are split by the enzyme preferentially (endo-enzymes) while a relatively slow change in viscosity indicates hydrolysis more at the end of the chains (exo-enzymes) [34]. To be classified as an endo enzyme, the relative viscosity decrease has to be considerably lower than the relative release of reducing sugars [35]. Reducing sugars concentrations are typically below $10 \%$ referred to total sugars at a concomitant viscosity reduction of $50 \%$ as a result of endo-acting enzymes.

Using viscosimetry, a $V_{\max }$ of $0.0041 \mathrm{mPa}$ and a $K_{\mathrm{M}}$ of $5.77 \mathrm{~g} / \mathrm{l}$ was determined for PG 1 , while PG 2 showed a $V_{\max }$ of $0.0129 \mathrm{mPa}$ and a $K_{\mathrm{M}}$ of $11.55 \mathrm{~g} / \mathrm{l}$.

4.2.3.2. NMR analysis. Reduced pentagalacturonic acid was used as a substrate for PG 1 and 2 to investigate the stereochemistry during hydrolysis. The configuration of the reducing ends in the products formed in $\mathrm{D}_{2} \mathrm{O}$ reaction mixtures was monitored by ${ }^{1} \mathrm{H}$ NMR spectroscopy as described previously for PGs from Aspergillus sp. [36].

Since PG 1 was reacting much slower on oligomers than PG 2 the double amount of activity was applied: $500 \mathrm{IU} / \mathrm{ml}$ for PG 1 and 250 IU/ml for PG 2. PentaGalU-ol was hydrolysed by both enzymes to triGalUA and diGalU-ol. The first cleavage was followed by hydrolysis of triGalUA to diGalUA and GalUA. This mode of attack of the substrates observed by TLC was in agreement with the ${ }^{1} \mathrm{H}$ NMR spectra of the enzyme substrate mixture recorded at various time intervals after enzyme addition.

Both enzymes lead to the same pattern of hydrolysis products according to NMR spectra (Figs. 5 and 6). The signals of pentaGalU-ol were replaced by signals of triGalUA, whereby the

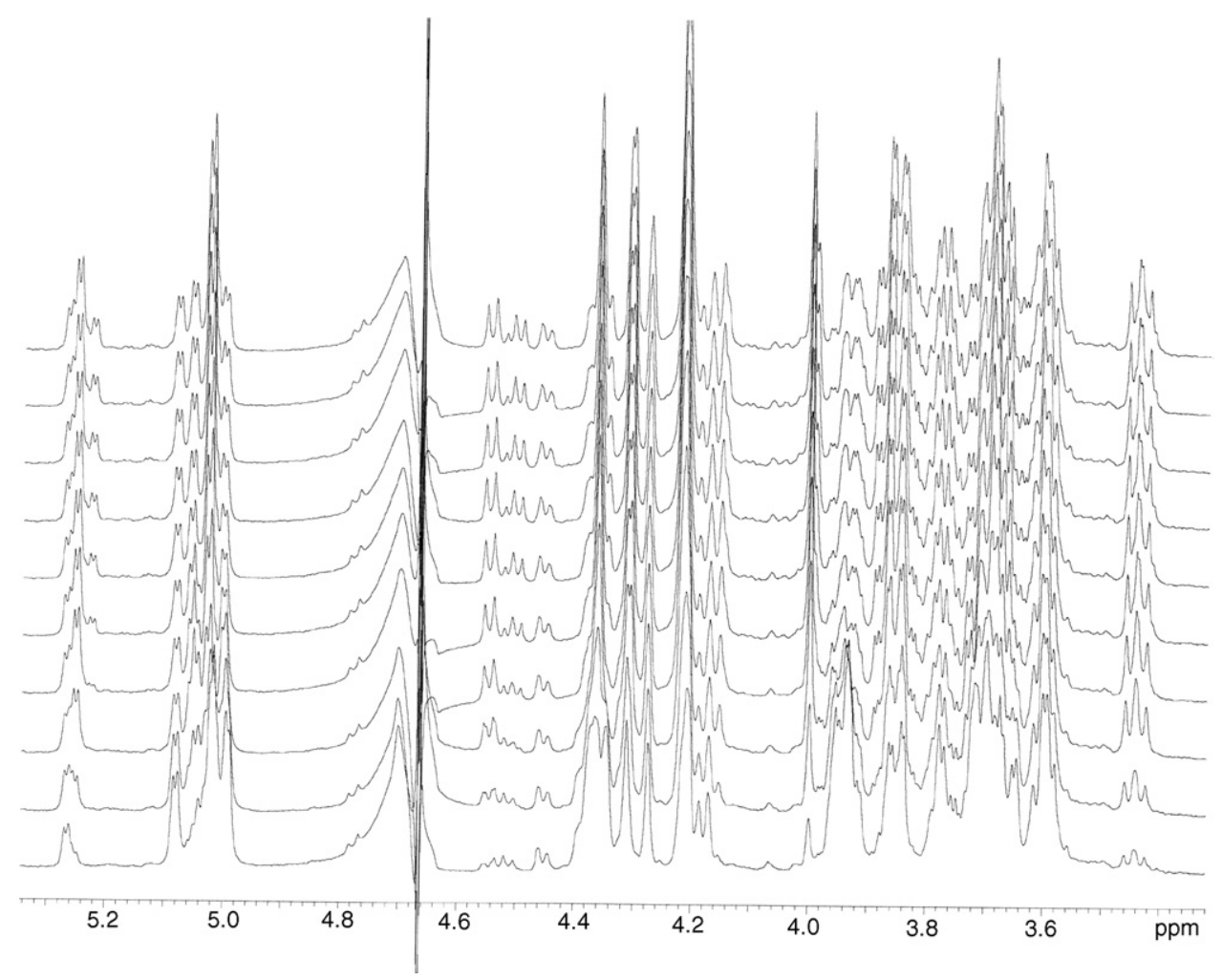

Fig. 5. ${ }^{1} \mathrm{H}$ NMR spectra of pentaGalU-ol hydrolysed by PG 1 . Spectra were taken every $30 \mathrm{~min}$ (important assignments see text). 


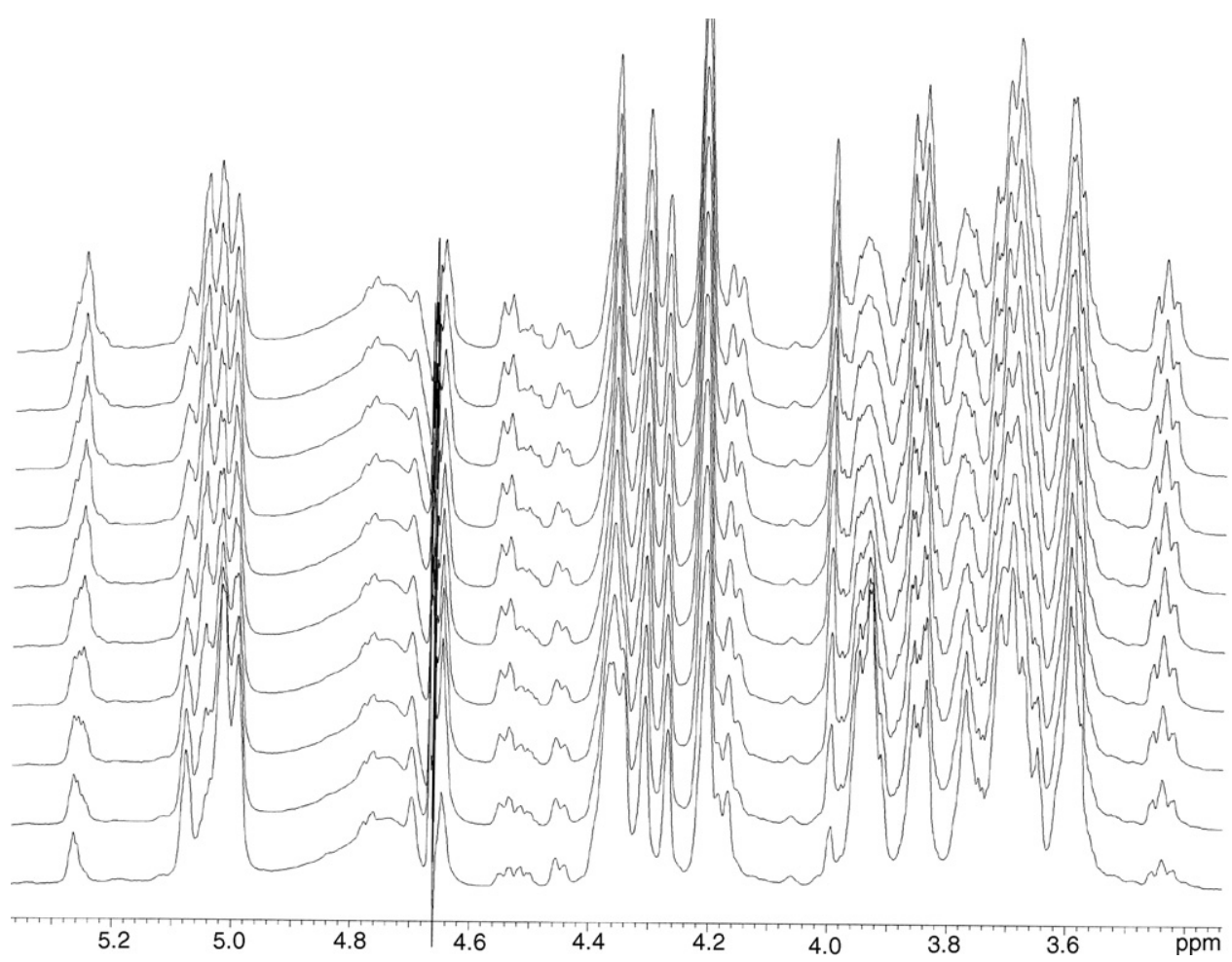

Fig. 6. ${ }^{1} \mathrm{H}$ NMR spectra of pentaGalU-ol hydrolysed by PG 2 . Spectra were taken every 5 min (important assignments see text).

$\beta$-anomer $(\mathrm{H}-1 \beta, 4.64 \mathrm{ppm})$ appeared slightly earlier than the $\alpha$-compound. Another important easily assignable resonance, which appeared in the spectra immediately after the formation of a new reducing end in $\beta$-configuration, is that of the $\mathrm{C}-2$ proton ( $\mathrm{H}-2 \beta$ multiplet at $3.53 \mathrm{ppm})$.

There was also some secondary cleavage of the trimer, although the reaction was slow. The pattern obtained was similar to the cleavage of the pentamer, $\beta$-GalUA $(\mathrm{H}-1 \beta, 4.60 \mathrm{ppm})$ was generated first followed by the $\alpha$-anomer ( $\mathrm{H}-1 \alpha, 5.31 \mathrm{ppm})$. Although these results indicate an inverting type of hydrolysis mechanism the simultaneously taking place mutarotation was influencing the results.

Summarizing these results, two polygalacturonases from Sclerotium rolfsii were purified by the new technology of free flow electrophoresis in isoelectric focusing mode to homogeneity using simply ammoniumsulphate precipitation as preliminary purification step. Both enzymes were endo-acting and inverting the stereochemical configuration of the newly formed reducing end. The described enzymes were applied for bioscouring of cotton [17]. Future experiments will focus on the elucidation of the structure/function relationship of these enzymes to explain the substrate specificities discussed here.

\section{Acknowledgements}

We thank Tecan Austria GmbH for the possibility to use their FFE prototype and Anton Paar GmbH for the measurements on AMVn viscosimeter and the great support from several sides. Also, we gratefully acknowledge the financial support of the project GRD1-1999-10671 by the European Commission.

\section{References}

[1] Sakai T, Sakamoto T, Hallaert J, Vandamme EJ. Pectin, pectinase and protopectinase: production, properties, and applications. Adv Appl Microbiol 1993;39:213-94.

[2] Ridley BL, O'Neill MA, Mohnen D. Pectins: structure, biosynthesis, and oligogalacturonide-related signaling. Phytochemistry 2001;57:92967.

[3] Lang C, Dörnenburg H. Perspectives in the biological function and the technological application of polygalacturonases. Appl Microbiol Biotechnol 2000;53:366-75.

[4] Kashyap DR, Vohra PK, Chopra S, Tewari R. Applications of pectinases in the commercial sector: a review. Bioresour Technol 2001;77:21527.

[5] Naidu GSN, Panda T. Production of pectolytic enzymes-a review. Bioprocess Eng 1998;19:355-61.

[6] Gummadi SN, Panda T. Purificationand biochamical properties of microbial pectinases-a review. Process Biochem 2003;38:987-96.

[7] Hymer W, Kirshan K, Kraemer W, Welsch J, Lanham W. Mammalian pituitary growth hormone: applications of free flow electrophoresis. Electrophoresis 2000;21:311-7.

[8] Poggel M, Melin T. Free-flow zone electrophoresis: a novel approach and scale-up for preparative protein separation. Electrophoresis 2001;22:1008-15.

[9] Sinnott ML. Catalytic mechanism of enzymic glycosyl transfer. Chem Rev 1990;90:1171-202.

[10] Haltrich D, Laussameyer B, Steiner W. Xylanase formation by Sclerotium rolfsii: effect of growth substrates and development of a culture medium using statistically designed experiments. Appl Microbiol Biotechnol 1994;42:522-30.

[11] Bailey MJ, Biely P, Poutanen K. Interlaboratory testing of methods for assay of xylanase activity. J Biotechnol 1992;23:257-70.

[12] Bradford MM. A rapid and sensitive method for the quantitation of micrgram quantities of protein utilizing the principle of protein dye-binding. Anal Biochem 1976;72:142-6.

[13] Laemmli UK. Cleavage of structural proteins during the assembly of the head of bacteriophage T4. Nature 1970;227:680-5. 
[14] Beguin P. Detection of cellulase activity in polyacrylamide gels using Congo Red-stained agar replicas. Anal Biochem 1983;131:333-6.

[15] Hricovini M, Bystricky S, Malovikova A. Conformations of (1 $\rightarrow 4)-$ linked [alpha]-galacturono-di- and -tri-saccharides in solution analysed by NMR measurements and theoretical calculations. Carbohydr Res 1991;220:23-31.

[16] Deshpade BS, Ambedkar SS, Channe PS, Shewale JG. Production of carbohydrases by Sclerotium rolfsii. Hindustan Antibiot Bull 1992;34:95-9.

[17] Schnitzhofer W, Kandelbauer A, Klug-Santner B, Onos M, Calafell M, Guebitz GM. Production of cellulase-free polygalacturonase preparation by Sclerotium rolfsii for bioscouring of cotton. J Nat Fibers 2006;3(2/3):19-38.

[18] Ried JL, Collmer A. Activity stain for rapid characterization of pectic enzymes in isoelectric focusing and sodium dodecyl sulfatepolyacrylamide gels. Appl Environ Microbiol 1985;50:615-22.

[19] Kaji A, Okada T. Purification and properties of an unusually acid-stable endo-polygalacturonase produced by Corticium rolfsii. Arch Biochem Biophys 1969;131:203-9.

[21] Sachslehner A, Grosswindhager N, Nidetzky B, Kulbe K, Haltrich D. Formation of endo-b-1,4-d-mannanase activity by various strains of Sclerotium and Athelia. In: International conference on biotechnology in pulp and paper industry. 1998.

[22] Devi NA, Rao AGA. Fractionation, purification, and preliminary characterization of polygalacturonases produced by Aspergillus carbonarius. Enzyme Microb Technol 1996;18:59-65.

[23] Martel MB, Letoublon R, Fevre M. Purification of endo polygalacturonases from Sclerotinia sclerotiorum: multiplicity of the complex enzyme system. Curr Microbiol 1996;33:243-8.

[24] Mwenje E, Ride JP. Purification and characterization of an endopolygalacturonase (PG 1) from a Zimbabwean species of Armillaria. Physiol Mol Plant Pathol 1999;55:131-9.

[25] Isshiki A, Akimitsu K, Nishio K, Tsukamoto M, Yamamoto H. Purification and characterization of an endopolygalacturonase from the rough lemon pathotype of Alternaria alternata, the cause of citrus brown spot disease. Physiol Mol Plant Pathol 1997;51:155-67.

[26] Gadre RV, Van Driessche G, Van Beeumen J, Bhat MK. Purification, characterisation and mode of action of an endo-polygalacturonase from the psychrophilic fungus Mucor flavus. Enzyme Microb Technol 2003;32:321-30.

[27] Stratilova E, Mislovicova D, Kacurakova M, Machova E, Kolarova $\mathrm{N}$, Markovic O, Jornvall $\mathrm{H}$. The glycoprotein character of multiple forms of Aspergillus polygalacturonase. J Protein Chem 1998;17:1739.

[28] Martel MB, Letoublon R, Fevre M. Purification and characterization of two endopolygalacturonases secreted during the early stages of the saprophytic growth of Sclerotinia sclerotiorum. FEMS Microbiol Lett 1998;158: 133-8.

[29] Bonnin E, Le Goff A, Körner R, Van Alebeek G-JWM, Christensen TMIE, Voragen AGJ, Roepstorff P, Caprari C, Thibault J-F. Study of the mode of action of endopolygalacturonase from Fusarium moniliforme. Biochim Biophys Acta 2001;1526:301-9.

[30] Pashova S, Slokoska L, Sheremetska P, Krumova E, Vasileva L, Angelova M. Physiological aspects of immobilised Aspergillus niger cells producing polymethylgalacturonase. Process Biochem 1999;35:15-9.

[31] Pashova S, Slokoska L, Krumova E, Angelova M. Induction of polymethylgalacturonase biosynthesis by immobilized cells of Aspergillus niger 26. Enzyme Microb Technol 1999;24:535-40.

[32] Sakai T, Sirasaka N, Hirano H, Kishida M, Kawasaki H. Isolation and expression of the gene which encodes a novel enzyme with polymethoxygalacturonate-degrading activity in Trichosporon penicillatum. FEBS Lett 1997;414:439-43.

[33] Benen JA, Kester HC, Visser J. Kinetic characterization of Aspergillus niger N400 endopolygalacturonases I, II and C. Eur J Biochem/FEBS 1999;259:577-85.

[34] Guebitz GM, Schnitzhofer W, Balakrishnan H, Steiner W. Two mannanases from Sclerotium rolfsii in total chlorine-free bleaching of softwood kraft pulp. J Biotechnol 1996;50(2/3):181-8.

[35] Shanley NA, van den Broek LAM, Voragen AGJ, Couglan MP. Isolation and characterisation of an endopolygalacturonase from Phanerochaete chrysosporium. J Biotechnol 1993;28:179-97.

[36] Biely P, Benen J, Heinrichova K, Kester HCM, Visser J. Inversion of configuration during hydrolysis of [alpha]-1,4-galacturonidic linkage by three Aspergillus polygalacturonases. FEBS Lett 1996;382:249-55. 